\title{
Presentation and Discussion of the UAM/Exercise I-1b: "Pin-Cell Burn-Up Benchmark" with the Hybrid Method
}

\author{
O. Cabellos \\ Department of Nuclear Engineering, Universidad Politécnica de Madrid, C/José Gutiérrez Abascal, 2, 28006 Madrid, Spain \\ Correspondence should be addressed to O. Cabellos; oscar.cabellos@upm.es
}

Received 6 September 2012; Accepted 10 December 2012

Academic Editor: Kostadin Ivanov

Copyright (c) 2013 O. Cabellos. This is an open access article distributed under the Creative Commons Attribution License, which permits unrestricted use, distribution, and reproduction in any medium, provided the original work is properly cited.

The aim of this work is to present the Exercise I- 1 b "pin-cell burn-up benchmark" proposed in the framework of OECD LWR UAM. Its objective is to address the uncertainty due to the basic nuclear data as well as the impact of processing the nuclear and covariance data in a pin-cell depletion calculation. Four different sensitivity/uncertainty propagation methodologies participate in this benchmark (GRS, NRG, UPM, and SNU\&KAERI). The paper describes the main features of the UPM model (hybrid method) compared with other methodologies. The requested output provided by UPM is presented, and it is discussed regarding the results of other methodologies.

\section{Introduction to the UAM/Exercise I-1b "Pin-Cell Burn-Up Benchmark"}

The general frame of the OECD LWR UAM benchmark consists of three phases with different exercises for each phase [1]. In the Phase I ("Neutronics Phase"), the Exercise 1 (I-1) "Cell Physics" is focused on the derivation of the multigroup microscopic cross-section libraries. Since the OECD LWR UAM benchmark establishes a framework for propagating cross-section uncertainties in LWR design and safety calculations, the objective of the extension of this Exercise I-1 to I-1b (cell burn-up physics) is to address the uncertainties in the depletion calculation due to the basic nuclear data as well as the impact of processing of nuclear and covariance data. The SCALE-6.0/1 covariance library [2] is the recommended source of cross-section data uncertainty. However, covariance data coming from other source of uncertainty together with evaluated nuclear data files can be used without any inconvenience.

To address this problem different sensitivity/uncertainty (S/U) tools can be used to propagate nuclear data (e.g., crosssection) uncertainties. The requested output of Exercise I$1 b$ is criticality value, reactions rates, collapsed cross-sections and nuclide concentrations as well as their uncertainties for depletion in a PWR pin-cell model.
1.1. Specifications of the "Pin-Cell Burn-Up Benchmark". The specification of this pin-cell benchmark is given in Tables 1 and 2 (geometry and material specifications), showing a typical configuration of a TMI-1 PWR unit cell.

The linear fuel density $(\mathrm{gU} / \mathrm{cm})$ calculated according to values taken from Tables 1 and 2 is $6.2784 \mathrm{gU} / \mathrm{cm}$. The average power density ( $\mathrm{W} / \mathrm{gU})$ can be assumed to be equal to $33.58 \mathrm{~W} / \mathrm{gU}$. The fuel sample is burned for a unique complete cycle, the length of the burn time, and subsequent cooling time is given in Table 3 . The specific power and the final cumulative burnup are also given, $61.28 \mathrm{GWd} / \mathrm{MTU}$.

Concerning boundary conditions, the following type of boundary conditions can be used: (a) for a "cylindrical pincell" model, reflective boundary conditions are utilized at the center-line boundary while white boundary conditions are applicable at the peripheries of the cell model; (b) for a "square pin-cell" model, reflective boundary conditions on all surfaces are applied. For depletion, it can be considered an infinite burn-up spectrum mode.

1.2. Requested Output of the "Pin-Cell Burn-Up Benchmark". Results and associated uncertainties are provided at eight burn-up steps: $0,10,20,30,40,50,60$, and shutdown (61.28) GWd/MTU. And, six additional decay steps are required at $1,3,5,10,50$, and 100 years of cooling time. The requested 
TABLE 1: Hot full power (HFP) conditions for fuel pin-cell burn-up benchmark.

\begin{tabular}{lc}
\hline Fuel temperature $(\mathrm{K})$ & 900.0 \\
Cladding temperature $(\mathrm{K})$ & 600.0 \\
Moderator (coolant) temperature $(\mathrm{K})$ & 562.0 \\
Moderator (coolant) density $\left(\mathrm{g} / \mathrm{cm}^{3}\right)$ & 0.7484 \\
Reactor power (MWt) & 2772.0 \\
Total number of fuel assemblies in the reactor core & 177 \\
Number of fuel rods per fuel assembly & 208 \\
Active core length $(\mathrm{mm})$ & 3571.20 \\
\hline
\end{tabular}

TABLE 2: Configuration of pin-cell burn-up benchmark.

\begin{tabular}{lc}
\hline Unit cell pitch $(\mathrm{mm})$ & 14.427 \\
Fuel pellet diameter $(\mathrm{mm})$ & 9.391 \\
Fuel pellet material & $\mathrm{UO}_{2}$ \\
Fuel density $\left(\mathrm{g} / \mathrm{cm}^{3}\right)$ & 10.283 \\
Fuel enrichment $(\mathrm{w} / \mathrm{o})$ & 4.85 \\
Cladding outside diameter $(\mathrm{mm})$ & 10.928 \\
Cladding thickness $(\mathrm{mm})$ & 0.673 \\
Cladding material & $\mathrm{Zircaloy}-4$ \\
Cladding density $\left(\mathrm{g} / \mathrm{cm}^{3}\right)$ & 6.55 \\
Gap material & $\mathrm{He}$ \\
Moderator material & $\mathrm{H}_{2} \mathrm{O}$ \\
\hline
\end{tabular}

TABLE 3: Simplified operating history data for pin-cell burn-up benchmark and specific power.

\begin{tabular}{lc}
\hline Operating cycle & 1 \\
Burn time (days) & 1825.0 \\
Final Burnup (GWd/MTU) & 61.28 \\
Downtime (days) & 1870.0 \\
Specific power (kW/kgU) & 33.58 \\
\hline
\end{tabular}

output can be summarized in the following three sets of information:

(i) criticality values: Kinf and nuclide reactions that contribute the most to the uncertainty in kinf;

(ii) reaction rates and collapsed macroscopic crosssections:

(a) Reaction rates (capture and fission) and uncertainties for major isotopes: ${ }^{235,238} \mathrm{U}$ and 239,240,241 $\mathrm{Pu}$;

(b) Two-group macroscopic cross-sections, fast and thermal, and associated uncertainties for the homogenized pin cell: absorption, fission, nufission, and diffusion coefficient. The thermal energy cutoff is $0.625 \mathrm{eV}$.

(iii) Number densities:

$$
\begin{aligned}
& \text { (a) actinides (15): } \quad{ }_{238,239,240,241,242}^{233,234,235,236,238} \mathrm{Uu} ; \quad{ }^{241,243} \mathrm{Am} ;{ }^{244,246} \mathrm{Cm} \text {; } \\
& { }^{243} \text {; }
\end{aligned}
$$

(b) fission products (36): ${ }^{95} \mathrm{Mo} ;{ }^{99} \mathrm{Tc} ;{ }^{101,106} \mathrm{Ru}$; ${ }^{103} \mathrm{Rh} ;{ }^{109} \mathrm{Ag} ;{ }^{133,134,135,137} \mathrm{Cs} ;{ }^{139} \mathrm{La} ;{ }^{140,142,144} \mathrm{Ce}$; 142,143,145,146,148,150 Nd; ${ }^{147,148,149,150,151,152,154}$ Sm; ${ }^{151,153,154,155} \mathrm{Eu} ;{ }^{154,155,156,158,160} \mathrm{Gd}$.

\section{Summary of Propagation Uncertainty Methodologies in Burn-Up Calculations}

The first phase of participation in this exercise was completed in April 2012 with a total of 4 participants: GRS, NRG, UPM, and SNU\&KAERI. Table 4 summarizes the main calculation methodologies and nuclear data libraries and their uncertainties. The results were presented at the Sixth Workshop (UAM-6) of OECD Benchmark for Uncertainty Analysis in Best-Estimate Modelling (UAM).

On one hand, depletion calculations are performed by GRS and UPM with SCALE6 code system [3], while NRG uses SERPENT code [4] and SNU\&KAERI participates in the benchmark with its own McCARD code [5], both Monte Carlo codes. On the other side, for uncertainty calculations, GRS and NRG use Monte Carlo techniques, GRS with a sampling methodology (XSUSA [6]) of multigroup crosssection libraries provided in SCALE6 format and NRG using the technique of Total Monte Carlo [7] with TENDL2011. UPM applies a hybrid method [8] based on determining the sensitivity coefficients with TSUNAMI code [9] and performing a Monte Carlo sampling to determine the uncertainty of the number densities; these uncertainties are computed with ACAB code [10]. McCARD code makes use of the technique of Adjoint Weighted Perturbation (AWP) method to predict the sensitivity coefficients.

Regarding cross-section covariance data, GRS, SNU\& KAERI, and UPM use SCALE6/COVA-44 groups. In addition, SNU\&KAERI provides results with uncertainties coming from JENDL3.3 and ENDF/B-VII.0. Figure 1 shows an example of cross-section covariance data taken from SCALE6.1/COVA-44G. In this figure, the original ${ }^{235} \mathrm{U}$ COVERX/SCALE6.1 file is processed with ANGELO, LAMBDA, and NJOY codes to visualize the correlation matrix. NRG uses TENDL2011 and their uncertainty for cross-section data libraries. In addition, NRG and UPM have carried out some calculations with the uncertainty provided in Fission Yields (TENDL2011, JEFF-3.1.1) and Decay Data (JEFF-3.1.1) libraries.

Next, the main characteristics of the uncertainty propagation methodologies used in this Benchmark are summarized, and the uncertainty propagation in number density is used as an example in the following Figures 2, 3, and 6.

(1) Figure 2 shows the calculation scheme of the Monte Carlo methodologies. NRG uses for each sampling a different nuclear data library TENDL2011; the generation of this library is done using the TASMAN code [7]. TASMAN is a computer code for the production of covariance data using results of the nuclear model code TALYS, and for automatic optimization of the TALYS results with respect to experimental data. It is assumed that each nuclear model (i.e., TALYS input) 
TABLE 4: List of participants and brief description of their methodologies used in this benchmark.

\begin{tabular}{|c|c|c|c|c|}
\hline $\begin{array}{l}\text { Institution } \\
\text { (country) }\end{array}$ & $\begin{array}{l}\text { Methodology/codes } \\
\text { (Nuclear data library) }\end{array}$ & Covariance data library & $\begin{array}{l}\text { Criticality calculation } \\
\text { methodology }\end{array}$ & Uncertainty methodology \\
\hline $\begin{array}{l}\text { GRS } \\
\text { (Germany) }\end{array}$ & $\begin{array}{l}\text { XSUSA/SCALE6.0 } \\
\text { TRITON } \\
\text { (BONAMI-CENTRM- } \\
\text { NEWT-ORIGENS) } \\
\text { (ENDF/B-VII.0) }\end{array}$ & $\begin{array}{l}\text { SCALE } 6.0 \\
\text { (44 groups) }\end{array}$ & 2-D-SN & $\begin{array}{l}\text { Sampling multigroups } \\
\text { libraries based on } \\
\text { uncertainties in nuclear } \\
\text { data libraries }\end{array}$ \\
\hline $\begin{array}{l}\text { NRG } \\
\text { (The Netherlands) }\end{array}$ & $\begin{array}{l}\text { TMC/SERPENT } \\
\text { (TENDL2011) }\end{array}$ & $\begin{array}{l}\text { XS and FYs } \\
\text { TENDL2011 }\end{array}$ & Monte Carlo & Total Monte Carlo \\
\hline $\begin{array}{l}\text { SNU\&KAERI } \\
\text { (South Korea) }\end{array}$ & $\begin{array}{l}\text { McCARD } \\
\text { (ENDF/B-VII.0) }\end{array}$ & $\begin{array}{l}\text { ENDF/B-VII.0 } \\
\text { JENDL3.3 } \\
\text { SCALE6.1 }\end{array}$ & Monte Carlo & $\begin{array}{l}\text { Monte Carlo uncertainty } \\
\text { propagation }\end{array}$ \\
\hline $\begin{array}{l}\text { UPM } \\
\text { (Spain) }\end{array}$ & $\begin{array}{l}\text { SCALE6.1 } \\
\text { TRITON/ACAB } \\
\text { Hybrid method } \\
\text { (TSUNAMI) } \\
\text { (ENDF/B-VII.0) }\end{array}$ & $\begin{array}{l}\text { SCALE } 6.1 \\
\text { (44groups) } \\
\text { FY \& Decay data } \\
\text { JEFF3.1.1 }\end{array}$ & 2-D-SN & $\begin{array}{l}\text { Hybrid method: } \\
\text { TSUNAMI and sampling in } \\
\text { inventory calculations }\end{array}$ \\
\hline
\end{tabular}

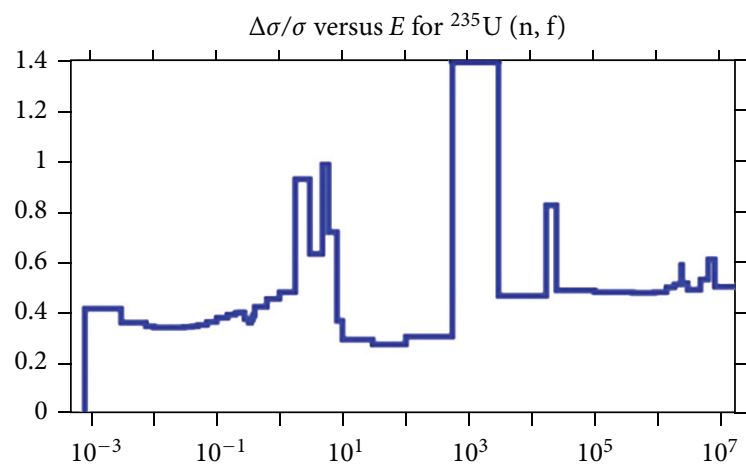

Ordinate scales are \% relative standard deviation and barns.

Abscissa scales are energy $(\mathrm{eV})$.
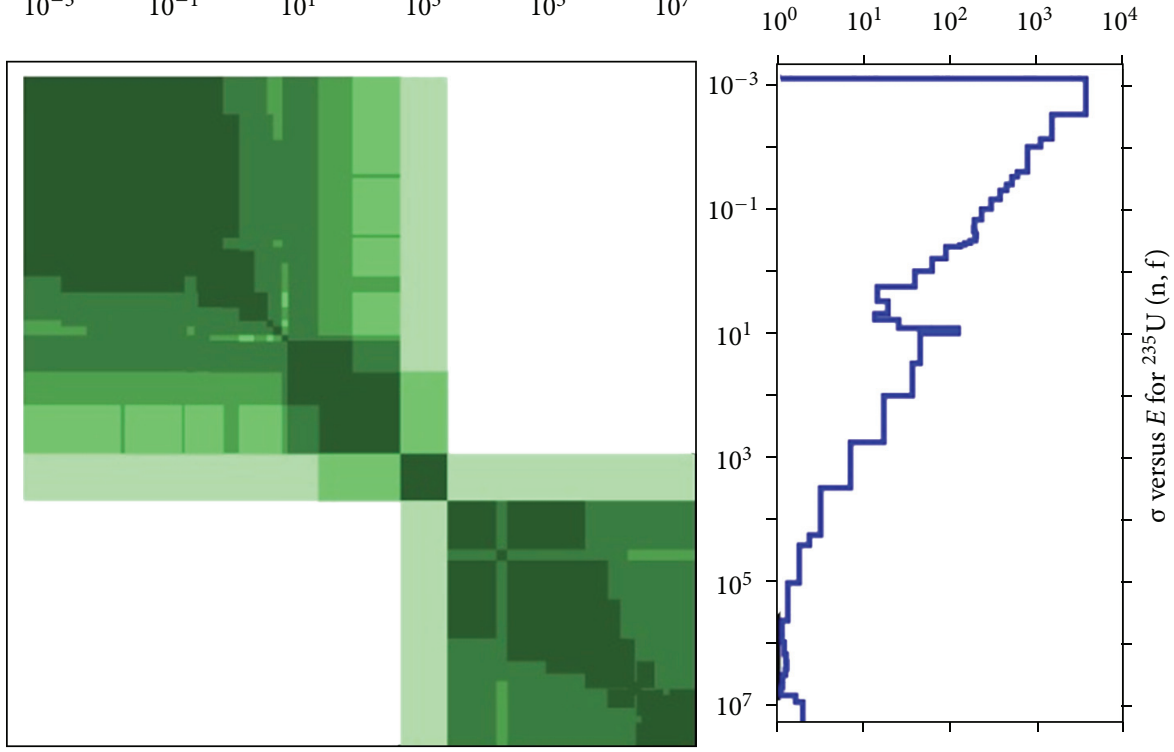

Correlation matrix
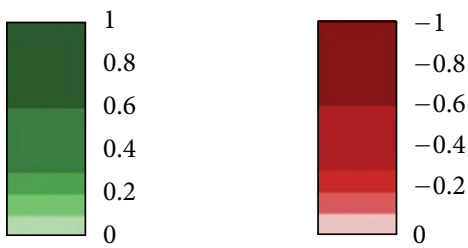

FIGURE 1: SCALE6.1 ${ }^{235}$ U-fission covariance data processed in 44 groups with ANGELO, LAMBDA, and NJOY99-364 codes. 


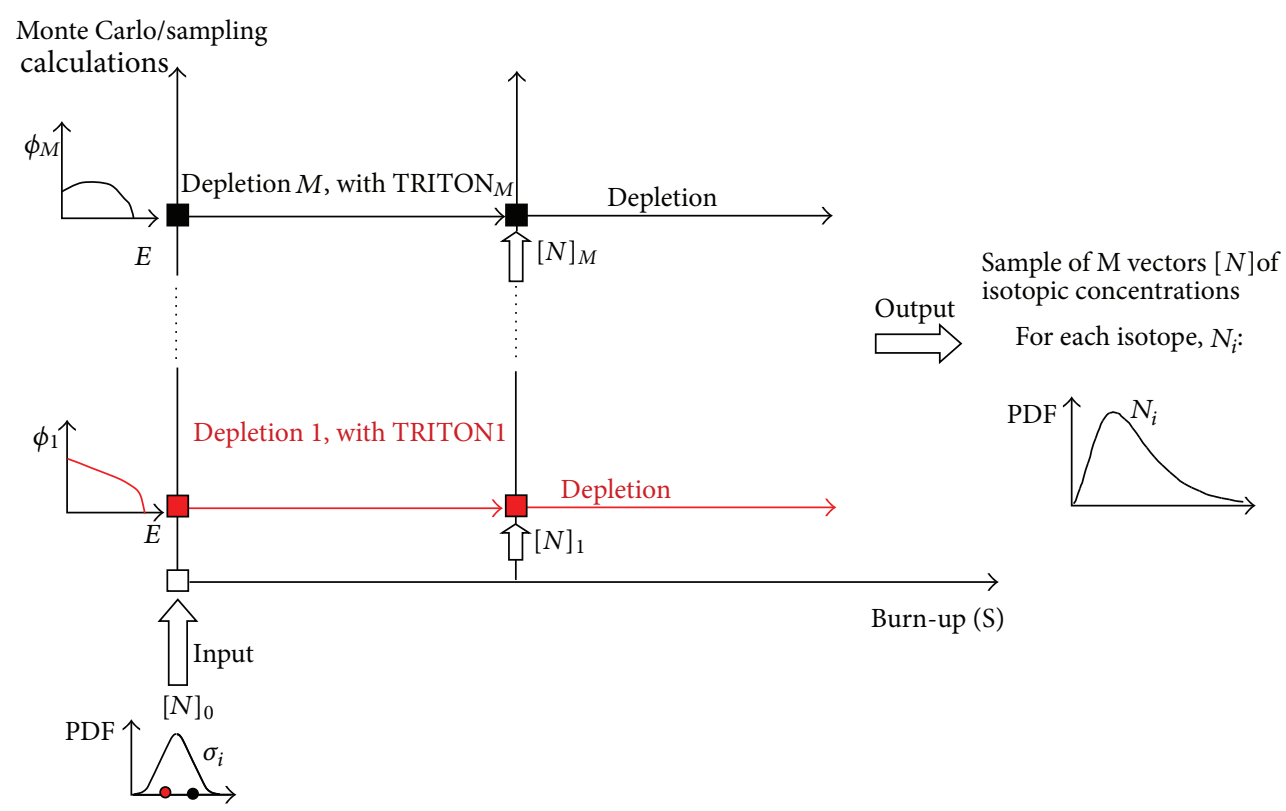

FIGURE 2: Simultaneous random sampling of the PDF of all the input parameters.

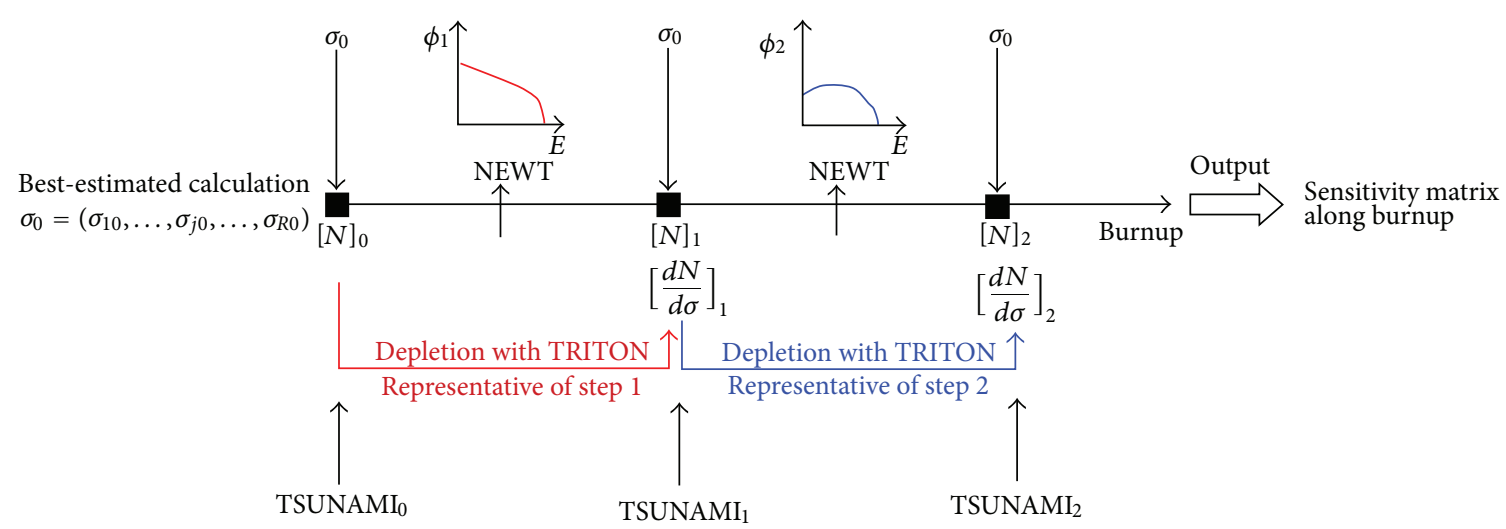

FIgURE 3: Procedure based on S/U.

parameter has its own uncertainty; running TALYS many times, it provides a sampling of ENDF files or a single file with full covariance information. GRS will generate a set of multigroup libraries in SCALE6 format; this sampling is done with the SCALE6.1/44groups covariance library using XSUSA code.

(2) The sensitivity/uncertainty procedure is based on a first order Taylor series approach. So, the number density can be written as

$N_{i}\left(\sigma^{\mathrm{eff}}\right)=N_{i}\left(\widehat{\sigma}^{\mathrm{eff}}\right)+\sum_{j=1}^{R}\left[\frac{\partial N_{i}}{\partial \sigma_{j}}\right]_{\sigma^{\mathrm{eff}}}\left(\sigma_{j}^{\mathrm{eff}}-\widehat{\sigma}_{j}^{\mathrm{eff}}\right)+\cdots$,

where $\sigma_{j}^{\text {eff }}=\sum_{g} \sigma_{j}^{g} \phi^{g}$.

We can define the sensitivity coefficients as $\rho_{i j}=$ $\left[\partial N_{i} / \partial \sigma_{j}\right]_{\sigma_{\text {eff }}}$, and $\varepsilon_{j}=\left(\sigma_{j}^{\text {eff }}-\widehat{\sigma}_{j}^{\text {eff }}\right)$ is the error in the 1-group effective cross-sections. This 1-group error depends explicitly on the uncertainty of cross-sections, and implicitly on the neutron-flux uncertainty,

$$
\varepsilon_{j}=\sum_{g=1}^{G} \phi^{g}\left(\sigma_{j}^{g}-\widehat{\sigma}_{j}^{g}\right)+\sum_{g=1}^{G} \sigma_{j}^{g}\left(\phi^{g}-\widehat{\phi}^{g}\right)=\phi^{T} \varepsilon_{\sigma_{j}}+\sigma_{j}^{T} \varepsilon_{\phi} .
$$

Here, $\varepsilon_{\sigma_{j}}$ is the error due to nuclear data and $\varepsilon_{\phi}$ is the error due to neutron-flux. The variance in the number density can be obtained using the sandwich formula:

$$
\begin{aligned}
& \operatorname{var} N \approx \mathbf{S}\left[C O V_{\sigma^{\text {eff }}}\right] \mathbf{S}^{\mathbf{T}}
\end{aligned}
$$

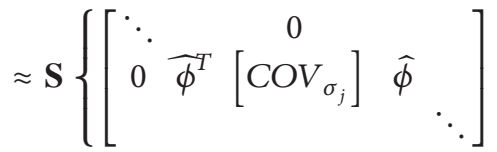

$$
\begin{aligned}
& \left.+\left[\begin{array}{cccc}
\ddots & 0 & & \\
0 & \widehat{\sigma}_{j}^{T} & {\left[\operatorname{COV}_{\phi}\right] \widehat{\sigma}_{j}} & \\
& & &
\end{array}\right]\right\} \mathbf{S}^{\mathbf{T}} .
\end{aligned}
$$


The first term propagates the multigroup cross-section uncertainty with no uncertainty in the neutron flux. And, the second term propagates the effect of this uncertainty with the uncertainty in the neutron flux.

If the uncertainty in the neutron flux can be considered negligible, a simple scheme of $\mathrm{S} / \mathrm{U}$ can be illustrated in Figure 3. In this case, TRITON code [3] is run to determine the number densities at different burnup steps, as a reference or nominal calculation without uncertainties. And, the number densities calculated in the nominal case are used to generate TSUNAMI [9] inputs at each burn-up step. With TSUNAMI code, S/U analysis can be provided for criticality $(d k / d \sigma, d k / d N, \ldots)$, twogroup cross-sections $\left(d \sum_{\mathrm{abs} 1} / d \sigma, d \sum_{\mathrm{abs} 1} / d N, \ldots\right)$ and reaction rates $\left(d \mathrm{RR}_{\mathrm{U} 235 \mathrm{cap}} / d \sigma, d \mathrm{RR}_{\mathrm{U} 235 \mathrm{cap}} / d N, \ldots\right)$. However, number density sensitivities $(d N / d \sigma)$ are not calculated with TSUNAMI code.

Once, the sensitivity coefficients are calculated by TSUNAMI code, the criticality uncertainty analysis based on "nuclear data uncertainties" can be formulated as follows: $k_{\text {eff }}$ it is explicitly dependent on the nuclear data (e.g., crosssections, nu-bar, ...) and implicitly dependent on the number density which characterizes the system:

$$
\operatorname{var}(k) \approx S_{k} V_{\sigma} S_{k}^{T}+S_{N} V_{N} S_{N}^{T}=\operatorname{var}\left(k_{\sigma}\right)+\operatorname{var}\left(k_{N}\right) .
$$

$S_{k}$ is the sensitivity coefficient explicitly of cross-sections $(\Delta k / \Delta \sigma)$ and $S_{N}$ is the sensitivity coefficient of number density, $(\Delta k / \Delta N)$; both are calculated by TSUNAMI code. Figures 4 and 5 show the $k$-eff integrated sensitivity coefficients for cross-section and number density at each burn-up step. In Figure 4, the evolution of $S_{k}$ shows the importance of ${ }^{239} \mathrm{Pu}$ at high burnups, mainly for nu-bar nuclear reaction. For ${ }^{238} \mathrm{U}$, $(n, \gamma)$ and $\left(n, n^{\prime}\right)$ reactions are the most important for all burnup. For ${ }^{235} \mathrm{U}$, sensitivity decreases with burn-up, being nu-bar with the highest value. Evolution of ${ }^{135} \mathrm{Xe}(n, \gamma)$ is also shown. Some "fission-gamma" cross-correlations for ${ }^{239} \mathrm{Pu}$ and ${ }^{235} \mathrm{U}$ are also illustrated. Figure 5 shows the integrated sensitivities, $S_{N}$, for the most important isotopes related with criticality: ${ }^{239,240,241} \mathrm{Pu},{ }^{235,238} \mathrm{U}$. Also, some important fission products are shown: ${ }^{135} \mathrm{Xe}$ and ${ }^{103} \mathrm{Rh}$.

$V_{\sigma}$ is the covariance cross-section data taken from SCALE6.1/COVA, and $V_{N}$ is the covariance number densities predicted by $\mathrm{ACAB}$ code. It can be calculated with the uncertainty due to cross-section, fission yield and/or decay data.

(3) Our ACAB code is used to propagate nuclear data uncertainty (cross-section, fission yield, and decay data) in the prediction of number density uncertainty:

$$
\operatorname{var}(N) \approx S_{N} V_{\sigma} S_{N}^{T}=\operatorname{var}\left(N_{\sigma}\right)
$$

$\mathrm{ACAB}$ accounts for the impact of nuclear data uncertainty as follows (see Figure 6). (i) In a first step, a coupled neutrondepletion calculation (without uncertainties) is carried out only once, taken the best-estimated values for all the parameters involved in the problem. (ii) In a second step, ACAB

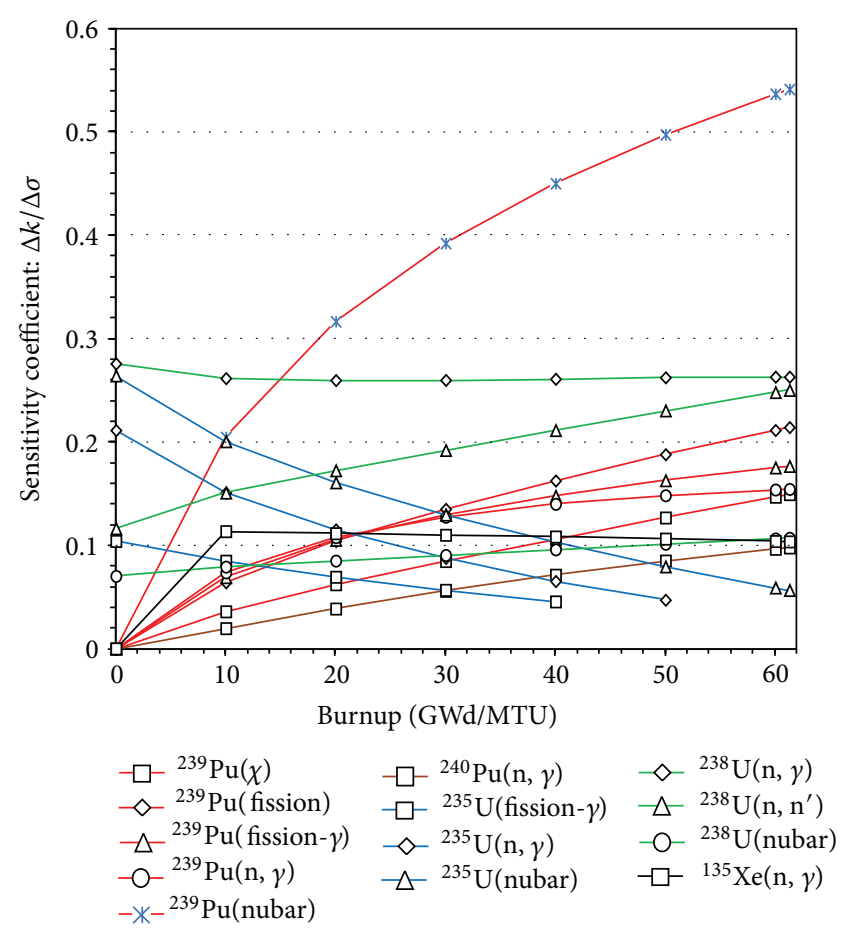

FIGURE 4: Sensitivity coefficients calculated with SCALE6.1/TRITON/TSUNAMI.

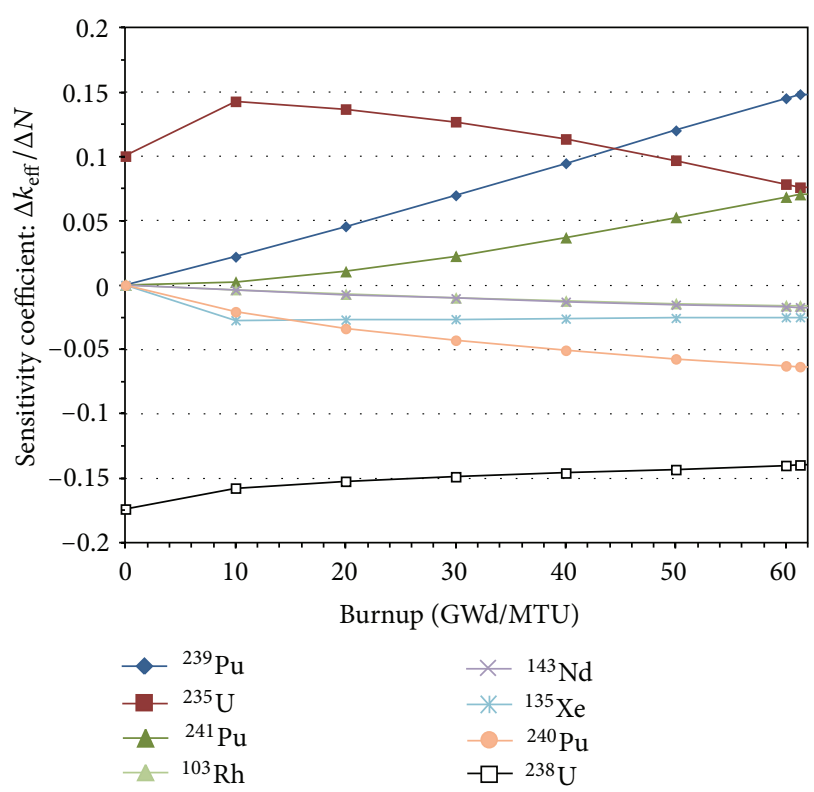

FIGURE 5: Sensitivity coefficients calculated with SCALE6.1/TRITON/TSUNAMI.

performs a simultaneous random sampling of the probability density functions (PDF) of all these variables: cross-section, fission yield, and decay data. Then, ACAB computes the isotopic concentrations at the end of each burn step, taking the fluxes halfway through each burn step determined in the best-estimated calculation. Then, only the depletion 


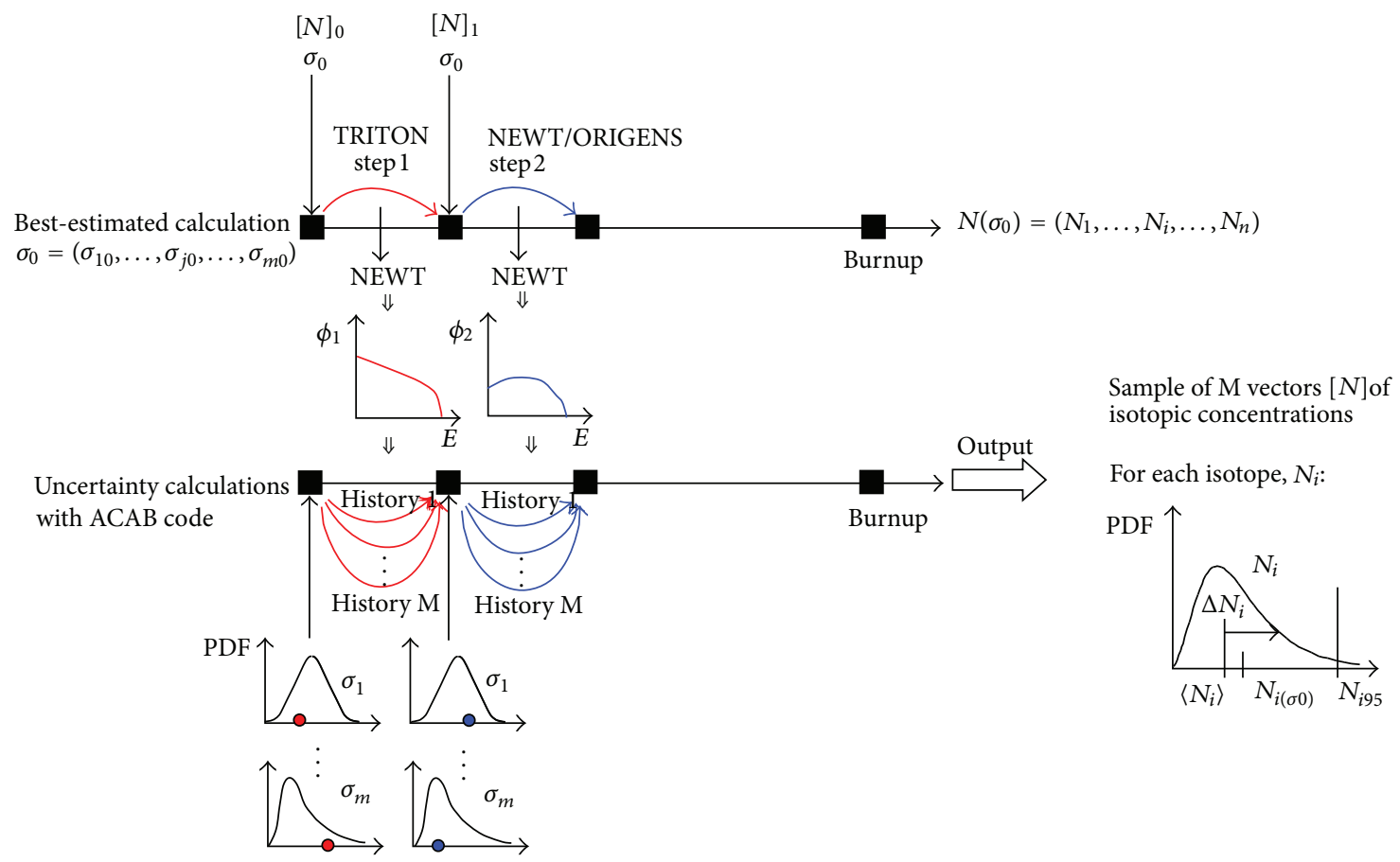

Figure 6: A Hybrid method used by ACAB code.

calculations are repeated or run many times. A statistical analysis of the results allows assessing the uncertainty in the calculated number density and determining $V_{N}$. Table 5 shows an example of this type of information.

\section{Results with the Hybrid Method}

In Table $6, k_{\text {eff }}$ and their associated uncertainty for PWR unitcell are summarized at four different burnups. The five most important nuclide reactions that contribute to uncertainty are identified: (i) for fresh fuel, $\mathrm{U}^{238}(n, \gamma), \mathrm{U}^{235}(\nu)$ and $(n, \gamma), \mathrm{U}^{238}\left(n, n^{\prime}\right), \mathrm{U}^{235}(n$, fiss- $\gamma)$, and (ii) for high burnup: $\mathrm{Pu}^{239}(\nu), \mathrm{U}^{238}(n, \gamma)$ and $\left(n, n^{\prime}\right), \mathrm{Pu}^{239}(n$, fiss $)$, and $(n$, fiss $-\gamma)$. In addition, the contribution of number density uncertainty, $\operatorname{var}\left(k_{N}\right)$, is evaluated, being the cross-sections and fission yields the most important contributions, and it can be concluded that the contribution of decay data uncertainty is negligible.

Table 7 shows the uncertainty of two-group crosssections: $\sum_{\text {abs-1 }}, \sum_{\text {abs-2 }}, \sum_{\text {fis-1 }}, \sum_{\text {fis-2 }}, v \sum_{\text {fis-1 }}, v \sum_{\text {fis-2 }}$, diff 1 , and $\operatorname{diff}_{2}$ (subscript 1 refers to fast group and subscript 2 to the thermal group). The low contribution of the uncertainty due to number density uncertainty except for thermal groups can be seen. The total uncertainty is about $1 \%$, and the contribution due to the uncertainty in fission yields is negligible.

As an example of integrated sensitivities of macroscopic two-group cross-sections, Figures 7 and 8 show these values for $\sum_{\text {abs-1 }} \cdot{ }^{238} \mathrm{U}$ is the most important contributor with the $\left(n, n^{\prime}\right)$ and $(n, \gamma)$ reactions.

Table 8 shows the uncertainty for the following capture and fission reaction rates: ${ }^{235,238} \mathrm{U}$ and ${ }^{239,240,241} \mathrm{Pu}$. The total uncertainty is in the range of $1 \%-3 \%$. In general, the uncertainty contribution due to the uncertainty in the number density $\left(\operatorname{var}\left(\mathrm{RR}_{N}\right)\right)$ is below the contribution due to cross-section $\left(\operatorname{var}\left(\mathrm{RR}_{\sigma}\right)\right)$, except for ${ }^{240} \mathrm{Pu}$ and ${ }^{241} \mathrm{Pu}$ reaction rates where this contribution is larger.

In Table 9, it can be seen that the number density uncertainty for some major and minor actinides due to crosssection data remains below 3\%. Larger uncertainties are predicted for minor actinides (e.g., ${ }^{246} \mathrm{Cm}$ ) and the uncertainty throughout irradiation period rises. And, it can be concluded that the uncertainty due to decay data uncertainty is negligible.

In Table 10, the uncertainty in the number of fission products due to cross-sections, decay, and fission yields data has been predicted. Some isotopes, ${ }^{155} \mathrm{Gd},{ }^{154,155} \mathrm{Eu}$, and ${ }^{149} \mathrm{Sm}$ show a relative error above $10 \%$, being the high uncertainty in cross-section data, the reason of this large uncertainty. In general, the uncertainty due to fission yields remain below $3 \%$, except for ${ }^{95} \mathrm{Mo}$ with $4.5 \%$ (with high sensitivity to ${ }^{95} \mathrm{Zr}$ fission yield) and ${ }^{149} \mathrm{Sm}$ with $4.7 \%$ (with high sensitivity to ${ }^{149} \mathrm{Pm}$ fission yield) [11]. For decay data uncertainties, the isotope ${ }^{151} \mathrm{Eu}$ reaches a maximum uncertainty of $3.2 \%$ as a consequence of the $6.7 \%$ relative error in the half-life of ${ }^{151} \mathrm{Sm}$.

\section{Conclusions and Comparison with Other Methodologies}

There has been a very small contribution of participants in the pin-cell burn-up benchmark, Exercise I-1b, with only 
TABLE 5: Correlation matrix, $V_{N}$, calculated at shutdown (61.28 GWd/TU) using SCALE6.1 cross-section data uncertainty. Column "e (\%)" is the relative error in \% for each isotope.

\begin{tabular}{|c|c|c|c|c|c|c|c|c|c|c|c|c|c|c|c|c|c|c|}
\hline & $e(\%)$ & $\mathrm{U}^{233}$ & $\mathrm{U}^{234}$ & $\mathrm{U}^{235}$ & $\mathrm{U}^{236}$ & $\mathrm{U}^{238}$ & $\mathrm{~Np}^{237}$ & $\mathrm{Pu}^{238}$ & $\mathrm{Pu}^{239}$ & $\mathrm{Pu}^{240}$ & $\mathrm{Pu}^{241}$ & $\mathrm{Pu}^{242}$ & $\mathrm{Am}^{241}$ & $\mathrm{Am}^{242}$ & $\mathrm{Am}^{243}$ & $\mathrm{Cm}^{242}$ & $\mathrm{Cm}^{243}$ & $\mathrm{Cm}^{244}$ \\
\hline $\mathrm{U}^{233}$ & 2.2 & 1.0 & 0.6 & & & & & & & & & & & & & & & \\
\hline $\mathrm{U}^{234}$ & 3.2 & 0.6 & 1.0 & & & & & & & & & & & & -0.1 & & & \\
\hline $\mathrm{U}^{235}$ & 0.6 & & & 1.0 & 0.3 & & & & & & & -0.1 & & & & & -0.1 & \\
\hline $\mathrm{U}^{236}$ & 0.4 & & & 0.3 & 1.0 & & 0.2 & & & & & & & & & & & \\
\hline $\mathrm{U}^{238}$ & 0.1 & & & & & 1.0 & & -0.2 & -0.3 & -0.2 & -0.2 & -0.3 & -0.2 & & -0.2 & -0.2 & & -0.2 \\
\hline $\mathrm{Np}^{237}$ & 0.8 & & & & 0.2 & & 1.0 & & & & & & & & & & & \\
\hline $\mathrm{Pu}^{238}$ & 0.9 & & & & & -0.2 & & 1.0 & & & 0.1 & 0.4 & & & 0.2 & 0.4 & 0.1 & 0.3 \\
\hline $\mathrm{Pu}^{239}$ & 1.4 & & & & & -0.3 & & & 1.0 & -0.4 & -0.2 & & & & & & & \\
\hline $\mathrm{Pu}^{240}$ & 2.0 & & & & & -0.2 & & & -0.4 & 1.0 & 0.3 & & 0.1 & & & & & \\
\hline $\mathrm{Pu}^{241}$ & 1.4 & & & & & -0.2 & & 0.1 & -0.2 & 0.3 & 1.0 & 0.3 & 0.5 & & 0.1 & 0.2 & & \\
\hline $\mathrm{Pu}^{242}$ & 1.4 & & & -0.1 & & -0.3 & & 0.4 & & & 0.3 & 1.0 & 0.4 & 0.2 & & 0.5 & 0.1 & 0.1 \\
\hline $\mathrm{Am}^{241}$ & 1.9 & & & & & -0.2 & & & & 0.1 & 0.5 & 0.4 & 1.0 & -0.2 & & -0.2 & & 0.1 \\
\hline $\mathrm{Am}^{242}$ & 5.8 & & & & & & & & & & & 0.2 & -0.2 & 1.0 & & 0.6 & 0.1 & \\
\hline $\mathrm{Am}^{243}$ & 2.0 & & -0.1 & & & -0.2 & & 0.2 & & & 0.1 & & & & 1.0 & 0.3 & 0.1 & 0.2 \\
\hline $\mathrm{Cm}^{242}$ & 1.7 & & & & & -0.2 & & 0.4 & & & 0.2 & 0.5 & -0.2 & 0.6 & 0.3 & 1.0 & & \\
\hline $\mathrm{Cm}^{243}$ & 6.0 & & & -0.1 & & & & 0.1 & & & & 0.1 & & 0.1 & 0.1 & & 1.0 & 0.1 \\
\hline $\mathrm{Cm}^{244}$ & 2.1 & & & & & -0.2 & & 0.3 & & & & 0.1 & 0.1 & & 0.2 & & 0.1 & 1.0 \\
\hline
\end{tabular}

TABLE 6: Uncertainties in criticality value, $k_{\text {eff }}$, with the main source of contributions. Cross-section uncertainties are taken from SCALE6.1/44-GROUP and fission yields and decay data source of uncertainty from JEFF-3.1.1.

\begin{tabular}{|c|c|c|c|c|c|c|c|}
\hline \multicolumn{2}{|c|}{$0 \mathrm{GWd} / \mathrm{MTU}$} & \multicolumn{2}{|c|}{$10 \mathrm{GWd} / \mathrm{MTU}$} & \multicolumn{2}{|c|}{$30 \mathrm{GWd} / \mathrm{MTU}$} & \multicolumn{2}{|c|}{$60 \mathrm{GWd} / \mathrm{MTU}$} \\
\hline Mean $k_{\text {eff }} 1.40$ & Rel. std. dev. (\%) & Mean $k_{\text {eff }} 1.25$ & Rel. std. dev. (\%) & Mean $k_{\text {eff }} 1.08$ & rel. std. dev. (\%) & Mean $k_{\text {eff }} 0.90$ & Rel. std. dev. (\%) \\
\hline $\mathrm{U}^{238}(n, \gamma)$ & 0.28 & $\mathrm{U}^{238}(n, € \gamma)$ & 0.26 & $\mathrm{Pu}^{239}$ (nubar) & 0.39 & $\mathrm{Pu}^{239}$ (nubar) & 0.54 \\
\hline $\mathrm{U}^{235}$ (nubar) & 0.26 & $\mathrm{Pu}^{239}$ (nubar) & 0.20 & $\mathrm{U}^{238}(n, \gamma)$ & 0.26 & $\mathrm{U}^{238}(n, \gamma)$ & 0.26 \\
\hline $\mathrm{U}^{235}(n, \gamma)$ & 0.21 & $\mathrm{U}^{235}$ (nubar) & 0.20 & $\mathrm{U}^{238}\left(n, n^{\prime}\right)$ & 0.19 & $\mathrm{U}^{238}\left(n, n^{\prime}\right)$ & 0.25 \\
\hline $\mathrm{U}^{238}\left(n, n^{\prime}\right)$ & 0.12 & $\mathrm{U}^{235}(n, \gamma)$ & 0.15 & $\mathrm{Pu}^{239}$ (fis) & 0.13 & $\mathrm{Pu}^{239}$ (fis) & 0.21 \\
\hline $\mathrm{U}^{235}$ ( $n, \gamma$-fiss $)$ & 0.10 & $\mathrm{U}^{238}\left(n, n^{\prime}\right)$ & 0.15 & $\mathrm{U}^{235}$ (nubar) & 0.13 & $\mathrm{Pu}^{239}(n, \gamma$-fiss $)$ & 0.18 \\
\hline$\cdots$ & $\cdots$ & $\cdots$ & $\cdots$ & $\cdots$ & $\cdots$ & $\cdots$ & $\cdots$ \\
\hline Total $\operatorname{var}\left(k_{\sigma}\right)$ & 0.49 & & 0.51 & & 0.63 & & 0.79 \\
\hline $\operatorname{var}\left(k_{N}\right) \_X S / S C A L E$ & 0.00 & & 0.19 & & 0.25 & & 0.35 \\
\hline $\operatorname{var}\left(k_{N}\right) \_$FYs & 0.00 & & 0.22 & & 0.22 & & 0.21 \\
\hline $\operatorname{var}\left(k_{N}\right)$ _Decay & 0.00 & & 0.00 & & 0.00 & & 0.00 \\
\hline Total $\operatorname{var}(k)$ & 0.49 & & 0.58 & & 0.71 & & 0.89 \\
\hline
\end{tabular}

four institutions: GRS, NRG, UPM, and SNU\&KAERI. However, the most representative methodologies in propagation uncertainties in depletion calculation are involved. Other institutions such as AREVA/NP and PSI have shown interest in participating in this exercise. Here, a comparison of these methodologies is summarized.

(1) Regarding the uncertainty in criticality, Table 6 shows the $k_{\text {eff }}$ relative uncertainty for the fresh fuel: approximately $0.5 \%$, and it reaches approximately $0.80 \%$ at high burn-up. GRS with XSUSA and SNU\&KAERI with McCARD code have obtained similar prediction. For fresh fuel, the most important contribution is due to the reaction ${ }^{238} \mathrm{U}(n$,gamma) and, at shutdown is, ${ }^{239} \mathrm{Pu}$ (nubar). Only, elastic reactions for ${ }^{235} \mathrm{U}$ and ${ }^{238} \mathrm{U}$ are predicted by GRS/XSUSA as important reactions to be taken into account. NRG/TENDL2011 includes ${ }^{235} \mathrm{U}$ and ${ }^{239} \mathrm{Pu}$ (chi) as other important reaction to be considered.

(2) The importance of different source of cross-section uncertainty has been evaluated by SNU\&KAERI. Thus, for fresh fuel the $k_{\text {eff }}$ relative uncertainty is $0.79 \%$ or $0.30 \%$, with uncertainty cross-section data ENDF/B.VII.1 or JENDL/-3.3, respectively.

(3) Comparing results between UPM and GRS (using both institutions similar uncertainty data and codes), it can be concluded that the linear approximation used by UPM neglects the possible correlation between the prediction of number densities and neutron transport calculation. At high burn-up the lower uncertainty in $k_{\text {eff }}$ predicted by GRS $(0.75 \%)$ with respect to UPM $(0.89 \%)$ shows a possible negative correlation between these terms. 
TABLE 7: Uncertainty in two-group cross-section data. Cross-section uncertainties are taken from SCALE6.1/44-GROUP.

\begin{tabular}{|c|c|c|c|c|c|c|}
\hline & & & $0 \mathrm{GWd} / \mathrm{MTU}$ & $10 \mathrm{GWd} / \mathrm{MTU}$ & $30 \mathrm{GWd} / \mathrm{MTU}$ & $60 \mathrm{GWd} / \mathrm{MTU}$ \\
\hline \multirow[t]{5}{*}{$\sum_{\text {abs-1 }}$} & & Mean value & $1.16 E-02$ & $1.20 E-02$ & $1.26 E-02$ & $1.31 E-02$ \\
\hline & \multirow{4}{*}{ Relative uncertainty (\%) } & $\operatorname{var}\left(\Sigma_{\sigma}\right)$ & 0.9 & 0.9 & 0.9 & 0.9 \\
\hline & & $\operatorname{var}\left(\Sigma_{N}\right)_{-} \Delta \mathrm{XS}$ & 0.0 & 0.1 & 0.1 & 0.1 \\
\hline & & $\operatorname{var}\left(\Sigma_{N}\right)_{-} \Delta \mathrm{FY}$ & 0.0 & 0.0 & 0.0 & 0.0 \\
\hline & & Total Uncertainty & 0.9 & 0.9 & 0.9 & 0.9 \\
\hline \multirow[t]{5}{*}{$\sum_{\text {abs-2 }}$} & & Mean value & $1.16 E-01$ & $1.30 E-01$ & $1.31 E-01$ & $1.20 E-01$ \\
\hline & \multirow{4}{*}{ Relative uncertainty (\%) } & $\operatorname{var}\left(\Sigma_{\sigma}\right)$ & 0.2 & 0.2 & 0.2 & 0.3 \\
\hline & & $\operatorname{var}\left(\Sigma_{N}\right)_{-} \Delta \mathrm{XS}$ & 0.0 & 0.3 & 0.4 & 0.6 \\
\hline & & $\operatorname{var}\left(\Sigma_{N}\right)_{-} \Delta \mathrm{FY}$ & 0.0 & 0.2 & 0.2 & 0.2 \\
\hline & & Total Uncertainty & 0.2 & 0.4 & 0.5 & 0.7 \\
\hline \multirow[t]{5}{*}{$\sum_{\text {fis- } 1}$} & & Mean value & $3.87 E-03$ & $3.42 E-03$ & $2.72 E-03$ & $2.02 E-03$ \\
\hline & \multirow{4}{*}{ Relative uncertainty (\%) } & $\operatorname{var}\left(\Sigma_{\sigma}\right)$ & 0.4 & 0.4 & 0.5 & 0.9 \\
\hline & & $\operatorname{var}\left(\Sigma_{N}\right)_{-} \Delta \mathrm{XS}$ & 0.0 & 0.1 & 0.2 & 0.3 \\
\hline & & $\operatorname{var}\left(\sum_{N}\right)_{-} \Delta \mathrm{FY}$ & 0.0 & 0.0 & 0.0 & 0.0 \\
\hline & & Total Uncertainty & 0.4 & 0.4 & 0.6 & 1.0 \\
\hline \multirow[t]{5}{*}{$\Sigma_{\text {fis-2 }}$} & & Mean value & $8.64 E-02$ & $8.48 E-02$ & $7.52 E-02$ & $5.84 E-02$ \\
\hline & \multirow{4}{*}{ Relative uncertainty (\%) } & $\operatorname{var}\left(\Sigma_{\sigma}\right)$ & 0.3 & 0.3 & 0.4 & 0.5 \\
\hline & & $\operatorname{var}\left(\Sigma_{N}\right)_{-} \Delta \mathrm{XS}$ & 0.0 & 0.2 & 0.4 & 0.7 \\
\hline & & $\operatorname{var}\left(\Sigma_{N}\right)_{-} \Delta \mathrm{FY}$ & 0.0 & 0.1 & 0.1 & 0.0 \\
\hline & & Total Uncertainty & 0.3 & 0.4 & 0.5 & 0.8 \\
\hline \multirow[t]{5}{*}{$v \sum_{\text {fis- } 1}$} & & Mean value & $9.76 E-03$ & $8.79 E-03$ & $7.20 E-03$ & $5.57 E-03$ \\
\hline & \multirow{4}{*}{ Relative uncertainty (\%) } & $\operatorname{var}\left(\Sigma_{\sigma}\right)$ & 0.5 & 0.6 & 0.7 & 1.1 \\
\hline & & $\operatorname{var}\left(\Sigma_{N}\right)_{-} \Delta \mathrm{XS}$ & 0.0 & 0.1 & 0.2 & 0.3 \\
\hline & & $\operatorname{var}\left(\sum_{N}\right)_{-} \Delta \mathrm{FY}$ & 0.0 & 0.0 & 0.0 & 0.0 \\
\hline & & Total Uncertainty & 0.5 & 0.6 & 0.8 & 1.2 \\
\hline \multirow[t]{5}{*}{$\nu \sum_{\text {fis-2 }}$} & & Mean value & $2.11 E-01$ & $2.15 E-01$ & $1.99 E-01$ & $1.62 E-01$ \\
\hline & \multirow{4}{*}{ Relative uncertainty (\%) } & $\operatorname{var}\left(\Sigma_{\sigma}\right)$ & 0.4 & 0.5 & 0.6 & 0.8 \\
\hline & & $\operatorname{var}\left(\Sigma_{N}\right)_{-} \Delta \mathrm{XS}$ & 0.0 & 0.3 & 0.4 & 0.7 \\
\hline & & $\operatorname{var}\left(\Sigma_{N}\right)_{-} \Delta \mathrm{FY}$ & 0.0 & 0.1 & 0.1 & 0.0 \\
\hline & & Total Uncertainty & 0.4 & 0.5 & 0.7 & 1.1 \\
\hline \multirow[t]{5}{*}{ diff-1 } & & Mean value & $2.51 E+00$ & $1.41 E+00$ & $1.99 E-01$ & $1.62 E-01$ \\
\hline & \multirow{4}{*}{ Relative uncertainty (\%) } & $\operatorname{var}\left(\Sigma_{\sigma}\right)$ & 0.9 & 0.9 & 0.9 & 0.9 \\
\hline & & $\operatorname{var}\left(\Sigma_{N}\right)_{-} \Delta \mathrm{XS}$ & 0.0 & 0.0 & 0.0 & 0.0 \\
\hline & & $\operatorname{var}\left(\Sigma_{N}\right)_{-} \Delta \mathrm{FY}$ & 0.0 & 0.0 & 0.0 & 0.0 \\
\hline & & Total Uncertainty & 0.9 & 0.9 & 0.9 & 0.9 \\
\hline \multirow[t]{5}{*}{ diff-2 } & & Mean value & $4.33 E-01$ & $3.62 E-01$ & $3.56 E-01$ & $3.54 E-01$ \\
\hline & \multirow{4}{*}{ Relative uncertainty (\%) } & $\operatorname{var}\left(\Sigma_{\sigma}\right)$ & 0.2 & 0.2 & 0.2 & 0.2 \\
\hline & & $\operatorname{var}\left(\Sigma_{N}\right)_{-} \Delta \mathrm{XS}$ & 0.0 & 0.0 & 0.0 & 0.0 \\
\hline & & $\operatorname{var}\left(\Sigma_{N}\right)_{-} \Delta \mathrm{FY}$ & 0.0 & 0.0 & 0.0 & 0.0 \\
\hline & & Total Uncertainty & 0.2 & 0.2 & 0.2 & 0.2 \\
\hline
\end{tabular}

(4) The importance of fission yields is analyzed by UPM and NRG with a relative uncertainty contribution to $k_{\text {eff }}$ approximately $0.2-0.3 \%$. The importance of decay data studied by UPM shows a negligible effect.

(5) For two group cross-sections and reaction rates, the relative uncertainty is in the range of $1-2 \%$. And comparing GRS between UPM, a positive correlation in two-group cross-sections between the prediction of number densities and neutron transport calculation due to the highest uncertainty values predicted by GRS is shown. For reaction rates, a negative correlation is found. NRG predicts larger uncertainties above $2 \%$ because of the TENDL2011 library.

(6) The uncertainty in the number density of major isotopes $\left({ }^{235} \mathrm{U},{ }^{239} \mathrm{Pu}, \ldots\right)$ is in the range of $1-3 \%$ increasing with burnup; higher uncertainty is predicted by GRS/XSUSA (3.5\% for ${ }^{242} \mathrm{Pu}$ ). For minor actinides, the highest uncertainty value is for ${ }^{246} \mathrm{Cm}$ 
TABLE 8: Uncertainty in reaction rates. Cross-section uncertainties are taken from SCALE6.1/44-GROUP.

\begin{tabular}{|c|c|c|c|c|c|c|}
\hline & & & $0 \mathrm{GWd} / \mathrm{MTU}$ & $10 \mathrm{GWd} / \mathrm{MTU}$ & $30 \mathrm{GWd} / \mathrm{MTU}$ & $60 \mathrm{GWd} / \mathrm{MTU}$ \\
\hline${ }^{235} \mathrm{U}$-cap & & Mean value & $9.10 E-02$ & $7.27 E-02$ & $4.76 E-02$ & $2.12 E-02$ \\
\hline & \multirow{2}{*}{ Relative uncertainty (\%) } & $\operatorname{var}\left(\mathrm{RR}_{\sigma}\right)$ & 1.8 & 1.8 & 1.8 & 1.8 \\
\hline & & $\operatorname{var}\left(\mathrm{RR}_{N}\right) \_\Delta \mathrm{XS}$ & 0.0 & 0.2 & 0.4 & 0.8 \\
\hline \multirow[t]{3}{*}{${ }^{235} \mathrm{U}$-fis } & & Mean value & $3.85 E-01$ & $2.97 E-01$ & $1.92 E-01$ & $8.70 E-02$ \\
\hline & \multirow{2}{*}{ Relative uncertainty (\%) } & $\operatorname{var}\left(\mathrm{RR}_{\sigma}\right)$ & 1.1 & 1.1 & 1.1 & 1.1 \\
\hline & & $\operatorname{var}\left(\mathrm{RR}_{N}\right) \_\Delta \mathrm{XS}$ & 0.0 & 0.2 & 0.5 & 0.8 \\
\hline \multirow[t]{3}{*}{${ }^{238} \mathrm{U}$-cap } & & Mean value & $1.83 E-01$ & $2.01 E-01$ & $2.29 E-01$ & $2.76 E-01$ \\
\hline & \multirow{2}{*}{ Relative uncertainty (\%) } & $\operatorname{var}\left(\mathrm{RR}_{\sigma}\right)$ & 1.4 & 1.3 & 1.3 & 1.3 \\
\hline & & $\operatorname{var}\left(\mathrm{RR}_{N}\right) \_\Delta \mathrm{XS}$ & 0.0 & 0.2 & 0.3 & 0.4 \\
\hline \multirow[t]{3}{*}{${ }^{238} \mathrm{U}$-fis } & & Mean value & $2.15 E-02$ & $2.43 E-02$ & $2.78 E-02$ & $3.27 E-02$ \\
\hline & \multirow{2}{*}{ Relative uncertainty (\%) } & $\operatorname{var}\left(\mathrm{RR}_{\sigma}\right)$ & 4.0 & 3.7 & 3.6 & 3.6 \\
\hline & & $\operatorname{var}\left(\mathrm{RR}_{N}\right) \_\Delta \mathrm{XS}$ & 0.0 & 0.2 & 0.3 & 0.4 \\
\hline \multirow[t]{3}{*}{${ }^{239} \mathrm{Pu}$-cap } & & Mean value & - & $3.93 E-02$ & $7.41 E-02$ & $1.00 E-01$ \\
\hline & \multirow{2}{*}{ Relative uncertainty (\%) } & $\operatorname{var}\left(\mathrm{RR}_{\sigma}\right)$ & - & 1.6 & 1.5 & 1.5 \\
\hline & & $\operatorname{var}\left(\mathrm{RR}_{N}\right) \_\Delta \mathrm{XS}$ & - & 0.9 & 0.7 & 0.7 \\
\hline \multirow[t]{3}{*}{${ }^{239} \mathrm{Pu}$-fiss } & & Mean value & - & $6.91 E-02$ & $1.33 E-01$ & $1.81 E-01$ \\
\hline & \multirow{2}{*}{ Relative uncertainty (\%) } & $\operatorname{var}\left(\mathrm{RR}_{\sigma}\right)$ & - & 1.3 & 1.3 & 1.3 \\
\hline & & $\operatorname{var}\left(\mathrm{RR}_{N}\right) \_\Delta \mathrm{XS}$ & - & 0.9 & 0.7 & 0.7 \\
\hline \multirow[t]{3}{*}{${ }^{240} \mathrm{Pu}$-cap } & & Mean value & - & $1.68 E-02$ & $5.00 E-02$ & $8.66 E-02$ \\
\hline & \multirow{2}{*}{ Relative uncertainty (\%) } & $\operatorname{var}\left(\mathrm{RR}_{\sigma}\right)$ & - & 1.3 & 1.3 & 1.4 \\
\hline & & $\operatorname{var}\left(\mathrm{RR}_{N}\right) \_\Delta \mathrm{XS}$ & - & 2.4 & 1.3 & 1.3 \\
\hline \multirow[t]{3}{*}{${ }^{240} \mathrm{Pu}$-fiss } & & Mean value & - & $6.10 E-05$ & $2.95 E-04$ & $6.67 E-04$ \\
\hline & \multirow{2}{*}{ Relative uncertainty (\%) } & $\operatorname{var}\left(\mathrm{RR}_{\sigma}\right)$ & - & 2.4 & 2.2 & 2.1 \\
\hline & & $\operatorname{var}\left(\mathrm{RR}_{N}\right) \_\Delta \mathrm{XS}$ & - & 3.1 & 2.2 & 2.1 \\
\hline \multirow[t]{3}{*}{${ }^{241} \mathrm{Pu}$-cap } & & Mean value & - & $1.13 E-03$ & $8.50 E-03$ & $2.05 E-02$ \\
\hline & \multirow{2}{*}{ Relative uncertainty (\%) } & $\operatorname{var}\left(\mathrm{RR}_{\sigma}\right)$ & - & 1.5 & 1.4 & 1.4 \\
\hline & & $\operatorname{var}\left(\mathrm{RR}_{N}\right) \_\Delta \mathrm{XS}$ & - & 2.0 & 1.7 & 1.5 \\
\hline \multirow[t]{3}{*}{${ }^{241} \mathrm{Pu}$-fiss } & & Mean value & - & $3.11 E-03$ & $2.37 E-02$ & $5.73 E-02$ \\
\hline & \multirow{2}{*}{ Relative uncertainty (\%) } & $\operatorname{var}\left(\mathrm{RR}_{\sigma}\right)$ & - & 1.3 & 1.3 & 1.3 \\
\hline & & $\operatorname{var}\left(\mathrm{RR}_{N}\right) \_\Delta \mathrm{XS}$ & - & 2.9 & 1.7 & 1.5 \\
\hline
\end{tabular}

TABLE 9: Uncertainty in number density for some important major and minor actinides. Cross-section uncertainties are taken from SCALE6.1/44-GROUP $(\triangle \mathrm{XS})$ and decay data $(\triangle \mathrm{DD})$ source of uncertainty from JEFF-3.1.1.

\begin{tabular}{|c|c|c|c|c|c|c|c|c|c|c|}
\hline & \multirow{3}{*}{$\begin{array}{c}0 \mathrm{GWd} / \mathrm{MTU} \\
\text { Mean }\end{array}$} & \multicolumn{3}{|c|}{$10 \mathrm{GWd} / \mathrm{MTU}$} & \multicolumn{3}{|c|}{$30 \mathrm{GWd} / \mathrm{MTU}$} & \multicolumn{3}{|c|}{$60 \mathrm{GWd} / \mathrm{MTU}$} \\
\hline & & \multirow[t]{2}{*}{ Mean } & \multicolumn{2}{|c|}{ Rel. std. dev. (\%) } & \multirow[t]{2}{*}{ Mean } & \multicolumn{2}{|c|}{ Rel. std. dev. (\%) } & \multirow[t]{2}{*}{ Mean } & \multicolumn{2}{|c|}{ Rel. std. dev. (\%) } \\
\hline & & & $\Delta \mathrm{XS}$ & $\Delta \mathrm{DD}$ & & $\Delta \mathrm{XS}$ & $\Delta \mathrm{DD}$ & & $\Delta \mathrm{XS}$ & $\Delta \mathrm{DD}$ \\
\hline${ }^{233} \mathrm{U}$ & $0.00 E+00$ & $5.94 E-11$ & 3.1 & 0.0 & $1.29 E-10$ & 2.1 & 0.0 & $1.41 E-10$ & 2.1 & 0.0 \\
\hline${ }^{234} \mathrm{U}$ & $1.17 E-05$ & $1.03 E-05$ & 1.0 & 0.0 & $7.94 E-06$ & 1.9 & 0.0 & $5.04 E-06$ & 3.1 & 0.0 \\
\hline${ }^{235} \mathrm{U}$ & $1.13 E-03$ & $8.71 E-04$ & 0.2 & 0.0 & $4.97 E-04$ & 0.3 & 0.0 & $1.74 E-04$ & 0.6 & 0.0 \\
\hline${ }^{236} \mathrm{U}$ & $0.00 E+00$ & $4.87 E-05$ & 0.8 & 0.0 & $1.15 E-04$ & 0.5 & 0.0 & $1.58 E-04$ & 0.4 & 0.0 \\
\hline${ }^{238} \mathrm{U}$ & $2.18 E-02$ & $2.17 E-02$ & 0.0 & 0.0 & $2.14 E-02$ & 0.1 & 0.0 & $2.08 E-02$ & 0.1 & 0.0 \\
\hline${ }^{237} \mathrm{~Np}$ & $0.00 E+00$ & $1.70 E-06$ & 1.2 & 0.0 & $8.76 E-06$ & 0.8 & 0.0 & $2.03 E-05$ & 0.8 & 0.0 \\
\hline${ }^{238} \mathrm{Pu}$ & $0.00 E+00$ & $1.24 E-07$ & 2.3 & 0.0 & $2.08 E-06$ & 1.4 & 0.0 & $1.07 E-05$ & 0.9 & 0.0 \\
\hline${ }^{239} \mathrm{Pu}$ & $0.00 E+00$ & $8.08 E-05$ & 1.2 & 0.0 & $1.46 E-04$ & 1.1 & 0.0 & $1.60 E-04$ & 1.3 & 0.0 \\
\hline${ }^{240} \mathrm{Pu}$ & $0.00 E+00$ & $9.36 E-06$ & 3.1 & 0.0 & $4.01 E-05$ & 2.1 & 0.0 & $7.59 E-05$ & 1.9 & 0.0 \\
\hline${ }^{241} \mathrm{Pu}$ & $0.00 E+00$ & $3.55 E-06$ & 2.9 & 0.0 & $2.46 E-05$ & 1.7 & 0.0 & $4.68 E-05$ & 1.5 & 0.0 \\
\hline${ }^{242} \mathrm{Pu}$ & $0.00 E+00$ & $1.98 E-07$ & 3.7 & 0.0 & $4.95 E-06$ & 1.9 & 0.0 & $2.31 E-05$ & 1.4 & 0.0 \\
\hline${ }^{241} \mathrm{Am}$ & $0.00 E+00$ & $3.66 E-08$ & 3.3 & 0.1 & $7.18 E-07$ & 1.9 & 0.1 & $1.99 E-06$ & 1.8 & 0.1 \\
\hline${ }^{243} \mathrm{Am}$ & $0.00 E+00$ & $9.64 E-09$ & 5.9 & 0.0 & $8.18 E-07$ & 3.0 & 0.0 & $7.00 E-06$ & 1.9 & 0.0 \\
\hline${ }^{244} \mathrm{Cm}$ & $0.00 E+00$ & $5.70 E-10$ & 6.9 & 0.0 & $1.76 E-07$ & 3.4 & 0.0 & $3.61 E-06$ & 2.1 & 0.0 \\
\hline
\end{tabular}


TABLE 10: Uncertainty in number density of some important fission products. Cross-section uncertainties are taken from SCALE6.1/44GROUP $(\triangle \mathrm{XS})$. Fission yields $(\triangle \mathrm{FYs})$ and decay data $(\triangle \mathrm{DD})$ source of uncertainty from JEFF-3.1.1.

\begin{tabular}{|c|c|c|c|c|c|c|c|c|c|c|c|c|c|}
\hline & \multirow{3}{*}{$\begin{array}{c}0 \mathrm{GWd} / \mathrm{MTU} \\
\text { Mean }\end{array}$} & \multicolumn{4}{|c|}{$10 \mathrm{GWd} / \mathrm{MTU}$} & \multicolumn{4}{|c|}{$30 \mathrm{GWd} / \mathrm{MTU}$} & \multicolumn{4}{|c|}{$60 \mathrm{GWd} / \mathrm{MTU}$} \\
\hline & & \multirow[t]{2}{*}{ Mean } & \multicolumn{3}{|c|}{ Rel. std. dev. (\%) } & \multirow[t]{2}{*}{ Mean } & \multicolumn{3}{|c|}{ Rel. std. dev. (\%) } & \multirow[t]{2}{*}{ Mean } & \multicolumn{3}{|c|}{ Rel. std. dev. (\%) } \\
\hline & & & $\Delta \mathrm{XS}$ & $\Delta \mathrm{DD}$ & $\Delta \mathrm{FYs}$ & & $\Delta \mathrm{XS}$ & $\Delta \mathrm{DD}$ & $\Delta \mathrm{FYs}$ & & $\Delta \mathrm{XS}$ & $\Delta \mathrm{DD}$ & $\Delta \mathrm{FYs}$ \\
\hline${ }^{154} \mathrm{Gd}$ & $0.00 E+00$ & $1.45 E-09$ & 11.8 & 0.1 & 2.3 & $4.20 E-08$ & 7.2 & 0.0 & 1.1 & $2.69 E-07$ & 5.2 & 0.0 & 0.8 \\
\hline${ }^{155} \mathrm{Gd}$ & $0.00 E+00$ & $5.06 E-10$ & 12.4 & 0.2 & 5.1 & $2.23 E-09$ & 15.2 & 0.2 & 2.4 & $5.80 E-09$ & 15.4 & 0.2 & 1.1 \\
\hline${ }^{156} \mathrm{Gd}$ & $0.00 E+00$ & $1.59 E-07$ & 3.9 & 0.1 & 3.0 & $1.34 E-06$ & 3.6 & 0.0 & 1.4 & $7.71 E-06$ & 4.1 & 0.0 & 0.8 \\
\hline${ }^{158} \mathrm{Gd}$ & $0.00 E+00$ & $6.06 E-08$ & 5.5 & 0.0 & 2.9 & $3.51 E-07$ & 5.3 & 0.0 & 1.8 & $1.43 E-06$ & 6.8 & 0.0 & 1.2 \\
\hline${ }^{160} \mathrm{Gd}$ & $0.00 E+00$ & $3.80 E-09$ & 1.3 & 0.0 & 4.8 & $2.25 E-08$ & 0.9 & 0.0 & 3.3 & $7.28 E-08$ & 0.7 & 0.0 & 2.9 \\
\hline${ }^{151} \mathrm{Eu}$ & $0.00 E+00$ & $5.98 E-10$ & 1.9 & 3.3 & 3.1 & $8.30 E-10$ & 2.0 & 3.1 & 2.5 & $7.89 E-10$ & 2.3 & 3.2 & 2.0 \\
\hline${ }^{153} \mathrm{Eu}$ & $0.00 E+00$ & $6.72 E-07$ & 2.2 & 0.0 & 2.1 & $3.31 E-06$ & 3.8 & 0.0 & 1.0 & $7.30 E-06$ & 6.0 & 0.0 & 0.7 \\
\hline${ }^{154} \mathrm{Eu}$ & $0.00 E+00$ & $6.87 E-08$ & 15.3 & 0.0 & 2.1 & $6.72 E-07$ & 11.3 & 0.0 & 1.0 & $1.94 E-06$ & 11.2 & 0.0 & 0.7 \\
\hline${ }^{155} \mathrm{Eu}$ & $0.00 E+00$ & $4.36 E-08$ & 14.1 & 0.0 & 5.9 & $1.98 E-07$ & 16.6 & 0.0 & 2.9 & $5.64 E-07$ & 18.6 & 0.0 & 1.3 \\
\hline${ }^{147} \mathrm{Sm}$ & $0.00 E+00$ & $4.24 E-07$ & 0.8 & 0.0 & 2.9 & $2.57 E-06$ & 0.8 & 0.0 & 1.6 & $5.23 E-06$ & 1.0 & 0.0 & 1.2 \\
\hline${ }^{148} \mathrm{Sm}$ & $0.00 E+00$ & $4.48 E-07$ & 2.6 & 0.0 & 3.0 & $3.65 E-06$ & 1.4 & 0.0 & 1.6 & $1.19 E-05$ & 0.8 & 0.0 & 1.2 \\
\hline${ }^{149} \mathrm{Sm}$ & $0.00 E+00$ & $1.17 E-07$ & 14.0 & 0.0 & 6.4 & $1.21 E-07$ & 14.3 & 0.0 & 5.7 & $1.05 E-07$ & 15.5 & 0.0 & 5.1 \\
\hline${ }^{150} \mathrm{Sm}$ & $0.00 E+00$ & $2.75 E-06$ & 1.3 & 0.0 & 2.4 & $9.21 E-06$ & 1.0 & 0.0 & 1.4 & $1.88 E-05$ & 0.9 & 0.0 & 1.0 \\
\hline${ }^{151} \mathrm{Sm}$ & $0.00 E+00$ & $3.92 E-07$ & 1.7 & 0.0 & 4.0 & $5.26 E-07$ & 1.8 & 0.0 & 3.3 & $6.33 E-07$ & 2.2 & 0.0 & 2.5 \\
\hline${ }^{152} \mathrm{Sm}$ & $0.00 E+00$ & $1.30 E-06$ & 1.0 & 0.0 & 1.9 & $3.47 E-06$ & 1.2 & 0.0 & 1.3 & $5.26 E-06$ & 1.6 & 0.0 & 0.9 \\
\hline${ }^{154} \mathrm{Sm}$ & $0.00 E+00$ & $2.54 E-07$ & 1.0 & 0.0 & 2.8 & $9.81 E-07$ & 0.6 & 0.0 & 1.8 & $2.47 E-06$ & 0.4 & 0.0 & 1.2 \\
\hline${ }^{142} \mathrm{Nd}$ & $0.00 E+00$ & $3.74 E-08$ & 3.8 & 0.0 & 3.0 & $4.40 E-07$ & 2.2 & 0.0 & 1.6 & $2.08 E-06$ & 1.5 & 0.0 & 1.1 \\
\hline${ }^{143} \mathrm{Nd}$ & $0.00 E+00$ & $1.23 E-05$ & 0.6 & 0.0 & 2.6 & $3.23 E-05$ & 0.5 & 0.0 & 1.4 & $4.79 E-05$ & 0.5 & 0.0 & 1.1 \\
\hline${ }^{145} \mathrm{Nd}$ & $0.00 E+00$ & $9.10 E-06$ & 0.7 & 0.0 & 2.8 & $2.46 E-05$ & 0.5 & 0.0 & 1.6 & $4.18 E-05$ & 0.5 & 0.0 & 1.1 \\
\hline${ }^{146} \mathrm{Nd}$ & $0.00 E+00$ & $7.51 E-06$ & 0.7 & 0.0 & 2.5 & $2.34 E-05$ & 0.5 & 0.0 & 1.3 & $5.03 E-05$ & 0.4 & 0.0 & 0.9 \\
\hline${ }^{148} \mathrm{Nd}$ & $0.00 E+00$ & $4.20 E-06$ & 0.7 & 0.0 & 2.1 & $1.24 E-05$ & 0.5 & 0.0 & 1.3 & $2.45 E-05$ & 0.4 & 0.0 & 0.9 \\
\hline${ }^{150} \mathrm{Nd}$ & $0.00 E+00$ & $1.76 E-06$ & 0.8 & 0.0 & 2.7 & $5.57 E-06$ & 0.5 & 0.0 & 1.8 & $1.18 E-05$ & 0.4 & 0.0 & 1.2 \\
\hline${ }^{133} \mathrm{Cs}$ & $0.00 E+00$ & $1.55 E-05$ & 0.7 & 0.0 & 2.0 & $4.36 E-05$ & 0.5 & 0.0 & 1.1 & $7.63 E-05$ & 0.4 & 0.0 & 0.9 \\
\hline${ }^{134} \mathrm{Cs}$ & $0.00 E+00$ & $4.83 E-07$ & 2.5 & 0.0 & 2.2 & $3.74 E-06$ & 1.6 & 0.0 & 1.1 & $1.16 E-05$ & 1.5 & 0.0 & 0.9 \\
\hline${ }^{135} \mathrm{Cs}$ & $0.00 E+00$ & $6.23 E-06$ & 1.4 & 0.1 & 2.5 & $1.82 E-05$ & 0.9 & 0.0 & 1.5 & $3.43 E-05$ & 0.8 & 0.0 & 1.0 \\
\hline${ }^{137} \mathrm{Cs}$ & $0.00 E+00$ & $1.51 E-05$ & 0.7 & 0.1 & 2.6 & $4.43 E-05$ & 0.5 & 0.0 & 1.6 & $8.59 E-05$ & 0.4 & 0.0 & 1.2 \\
\hline${ }^{139} \mathrm{La}$ & $0.00 E+00$ & $1.54 E-05$ & 0.7 & 0.0 & 2.4 & $4.46 E-05$ & 0.5 & 0.0 & 1.6 & $8.57 E-05$ & 0.3 & 0.0 & 1.2 \\
\hline${ }^{140} \mathrm{Ce}$ & $0.00 E+00$ & $1.39 E-05$ & 0.7 & 0.0 & 2.6 & $4.29 E-05$ & 0.5 & 0.0 & 1.5 & $8.48 E-05$ & 0.3 & 0.0 & 1.1 \\
\hline${ }^{142} \mathrm{Ce}$ & $0.00 E+00$ & $1.40 E-05$ & 0.7 & 0.0 & 2.6 & $4.05 E-05$ & 0.5 & 0.0 & 1.5 & $7.75 E-05$ & 0.3 & 0.0 & 1.1 \\
\hline${ }^{144} \mathrm{Ce}$ & $0.00 E+00$ & $9.12 E-06$ & 0.7 & 0.0 & 2.3 & $1.45 E-05$ & 0.5 & 0.0 & 1.7 & $1.44 E-05$ & 0.5 & 0.0 & 1.6 \\
\hline${ }^{95} \mathrm{Mo}$ & $0.00 E+00$ & $8.36 E-06$ & 1.0 & 0.0 & 9.7 & $3.55 E-05$ & 0.7 & 0.0 & 6.8 & $6.90 E-05$ & 0.5 & 0.0 & 4.8 \\
\hline${ }^{99} \mathrm{Tc}$ & $0.00 E+00$ & $1.47 E-05$ & 0.7 & 0.0 & 2.6 & $4.15 E-05$ & 0.5 & 0.0 & 1.6 & $7.44 E-05$ & 0.4 & 0.0 & 1.3 \\
\hline${ }^{101} \mathrm{Ru}$ & $0.00 E+00$ & $1.29 E-05$ & 0.7 & 0.0 & 2.8 & $3.82 E-05$ & 0.5 & 0.0 & 1.8 & $7.40 E-05$ & 0.4 & 0.0 & 1.2 \\
\hline${ }^{106} \mathrm{Ru}$ & $0.00 E+00$ & $1.80 E-06$ & 1.2 & 0.0 & 3.9 & $6.14 E-06$ & 0.7 & 0.0 & 2.2 & $1.18 E-05$ & 0.5 & 0.0 & 1.8 \\
\hline${ }^{103} \mathrm{Rh}$ & $0.00 E+00$ & $6.45 E-06$ & 1.3 & 0.0 & 3.0 & $2.11 E-05$ & 1.7 & 0.0 & 1.8 & $3.66 E-05$ & 2.4 & 0.0 & 1.3 \\
\hline${ }^{109} \mathrm{Ag}$ & $0.00 E+00$ & $4.50 E-07$ & 1.6 & 0.0 & 3.9 & $2.55 E-06$ & 1.9 & 0.0 & 1.8 & $7.00 E-06$ & 2.6 & 0.0 & 1.2 \\
\hline
\end{tabular}

with $13.9 \%$ and $4.0 \%$, predicted by GRS and UPM, respectively. NRG with TENDL2011 predicts similar values to UPM.

(7) For number density of fission products, NRG predicts larger uncertainty values than UPM and GRS, with a maximum uncertainty in ${ }^{147} \mathrm{Sm}$ of $31.7 \%$. For this isotope, GRS and UPM predict an uncertainty approximately $2 \%$. So, the influence of TENDL2011 in the prediction of fission products is quite large. Decay data uncertainty is analyzed by UPM showing only an important uncertainty of $3.3 \%$ in ${ }^{151} \mathrm{Eu}$.
The contribution of fission yield data uncertainty is also studied by UPM; the predicted number density uncertainty is in the range of $1-4 \%$, with a maximum value for ${ }^{95}$ Mo with $4.8 \%$. And, for uncertainty crosssection, the largest uncertainties found by UPM are ${ }^{155} \mathrm{Gd}(15.4 \%),{ }^{155} \mathrm{Eu}(18.6 \%)$, and ${ }^{149} \mathrm{Sm}$ (15.5\%). For these isotopes, GRS predicts lower uncertainty: ${ }^{155} \mathrm{Gd}$ (5.3\%), ${ }^{155} \mathrm{Eu}(5.5 \%)$, and ${ }^{149} \mathrm{Sm}(2.5 \%)$.

(8) In the case of ${ }^{155} \mathrm{Gd}$ (generated by $\beta$-decay of ${ }^{155} \mathrm{Eu}$ ), it shows higher sensitivities to ${ }^{153,155} \operatorname{Eu}(n, \gamma)$ reaction 


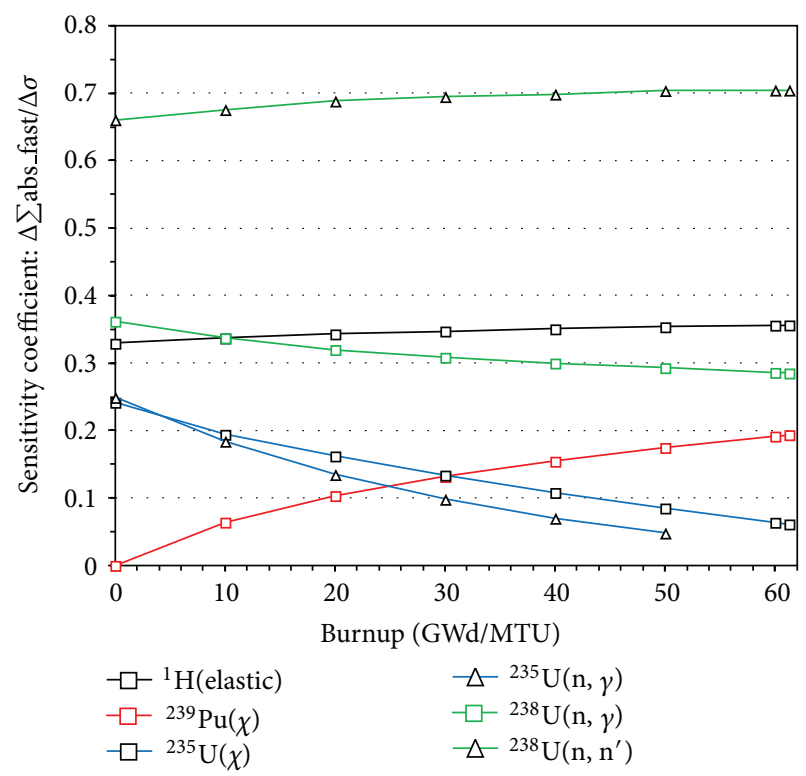

FIGURE 7: Sensitivity coefficients calculated with SCALE6.1/TRITON/TSUNAMI.

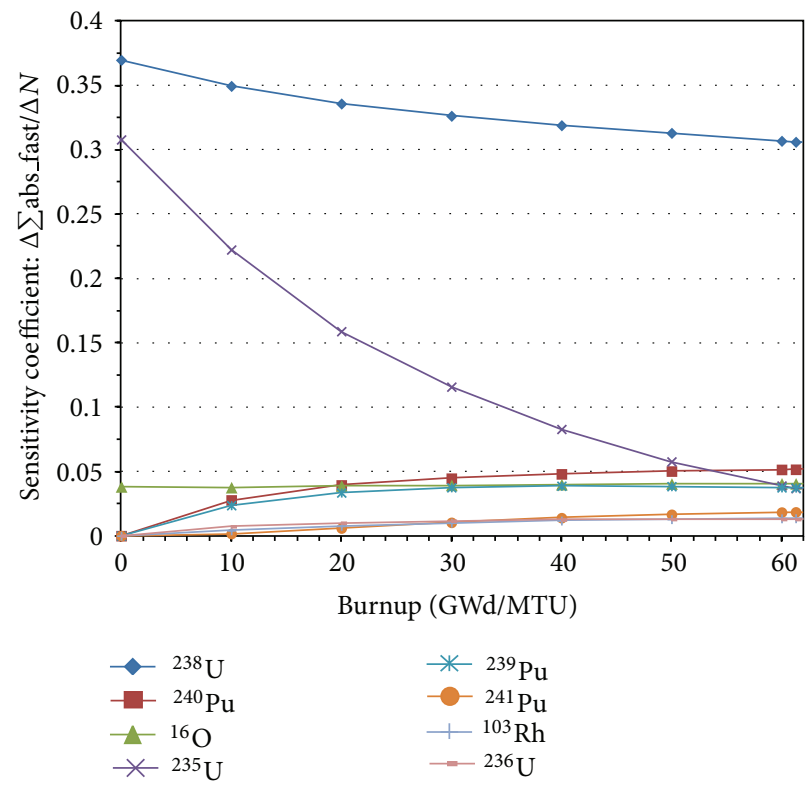

FIGURE 8: Sensitivity coefficients calculated with SCALE6.1/TRITON/TSUNAMI.

and ${ }^{155} \mathrm{Eu}$ fission yield. For ${ }^{149} \mathrm{Sm}$ (important contribution generated by $\beta$-decay of ${ }^{149} \mathrm{Pm}$ ) the higher sensitivities are due to ${ }^{149} \mathrm{Sm}(n, \gamma)$ and ${ }^{149} \mathrm{Pm}$ fission yield.

It is expected that new contributions for this benchmark will supply additional information to define the output range of uncertainty of this Exercise I-1b. And, as complete covariance data in ENDF/B-VII.1, JEFF-3.2, and JENDL-4.x become available, exercise I-1b can be performed as originally designed and results compared with the SCALE6/44GROUPS library supplying additional valuable information.

Finally, a general recommendation of this work should be the definition of input uncertainties for the following UAM Exercises. In particular one of the next steps in the roadmap of OECD LWR UAM benchmark is Phase II ("Core Phase") and in particular is the "Exercise II-2: Time-Dependent Neutronics": where neutron kinetics and fuel depletion stand-alone performance will be assessed. From the point of view of burn-up calculations, it can be considered a long-term time phenomena described by fuel assembly depletion performance (used for core design and fuel management). The objective of this Exercise II- 2 will be to determine the uncertainty in predicting the relative power over time of a core after a short-term reactivity change as well as during longer-term depletion cases.

\section{Acknowledgment}

This work is performed in the framework of the agreement in the area of Burn-Up Credit (P090531725) and Propagation of Uncertainties (P110530207) in Criticality Safety between the Spanish Nuclear Safety Council (CSN) and the Universidad Politécnica de Madrid (UPM).

\section{References}

[1] M. N. Avramova and K. N. Ivanov, "Verification, validation and uncertainty quantification in multi-physics modeling for nuclear reactor design and safety analysis," Progress in Nuclear Energy, vol. 52, no. 7, pp. 601-614, 2010.

[2] ZZ-SCALE6. 0/COVA-44G, USCD1236/02 OECD-NEA Data Bank.

[3] B. T. Rearden et al., ORNL/TM-2005/39 Version 6, vol. I, Sect. C9.

[4] J. Leppänen and M. Pusa, "Burnup calculation capability in the PSG2/Serpent Monte Carlo reactor physics code," in Proceedings of the International Conference on Mathematics, Computational Methods and Reactor Physics (M and C '09), pp. 1662-1673, Saratoga Springs, New York, NY, USA, May 2009.

[5] H. J. Park, H. J. Shim, and C. H. Kim, "Uncertainty propagation in monte carlo depletion analysis," Nuclear Science and Engineering, vol. 167, no. 3, pp. 196-208, 2011.

[6] M. Klein, L. Gallner, B. Krzykacz-Hausmann, A. Pautz, and W. Zwermann, "Influence of nuclear data uncertainties on reactor core calculations," Kerntechnik, vol. 76, no. 3, pp. 174-178, 2011.

[7] D. Rochman, A. J. Koning, S. C. van der Marck, A. Hogenbirk, and C. M. Sciolla, "Nuclear data uncertainty propagation: perturbation vs. Monte Carlo," Annals of Nuclear Energy, vol. 38, no. 5, pp. 942-952, 2011.

[8] N. García-Herranz, O. Cabellos, J. Sanz, J. Juan, and J. C. Kuijper, "Propagation of statistical and nuclear data uncertainties in Monte Carlo burn-up calculations," Annals of Nuclear Energy, vol. 35, no. 4, pp. 714-730, 2008.

[9] B. T. Rearden, "TSUNAMI sensitivity and uncertainty analysis capabilities in SCALE 5. no. 1," Transactions of the American Nuclear Society, vol. 97, pp. 604-605, 2007. 
[10] J. Sanz, O. Cabellos, and N. García-Herranz, ACAB-2008: Activation Code V2008, NEA-1839, OECD/NEA Data Bank, 2008.

[11] G. Chiba, K. Okumura, A. Oizumi, and M. Saito, "Sensitivity analysis of fission product concentrations for light water reactor burned fuel," Journal of Nuclear Science and Technology, vol. 47, no. 7, pp. 652-660, 2010. 


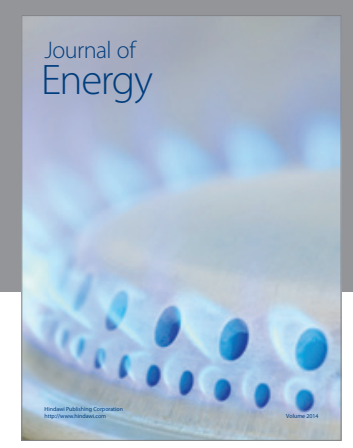

Journal of

Industrial Engineering
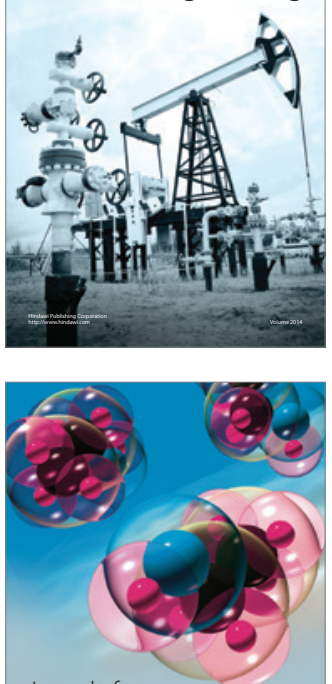

Fuels
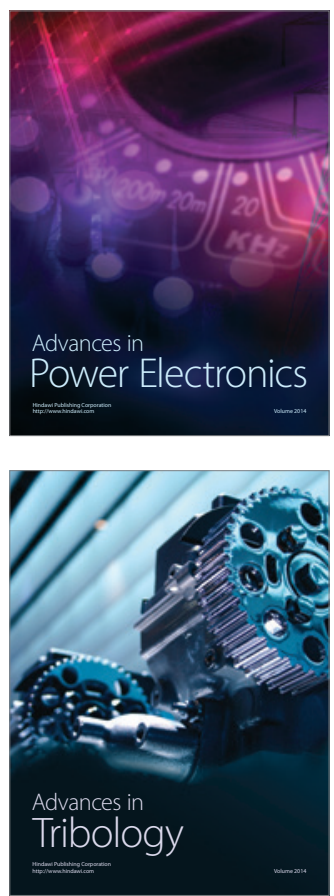

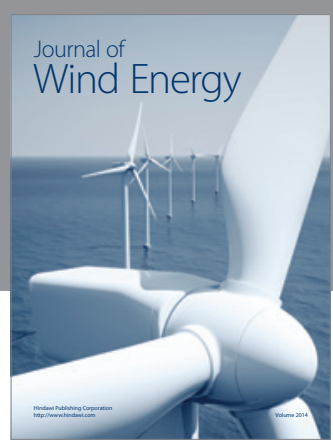

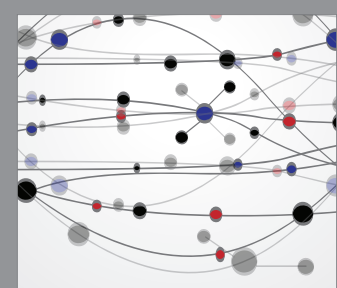

The Scientific World Journal

Submit your manuscripts at http://www.hindawi.com

Journal of

Structures
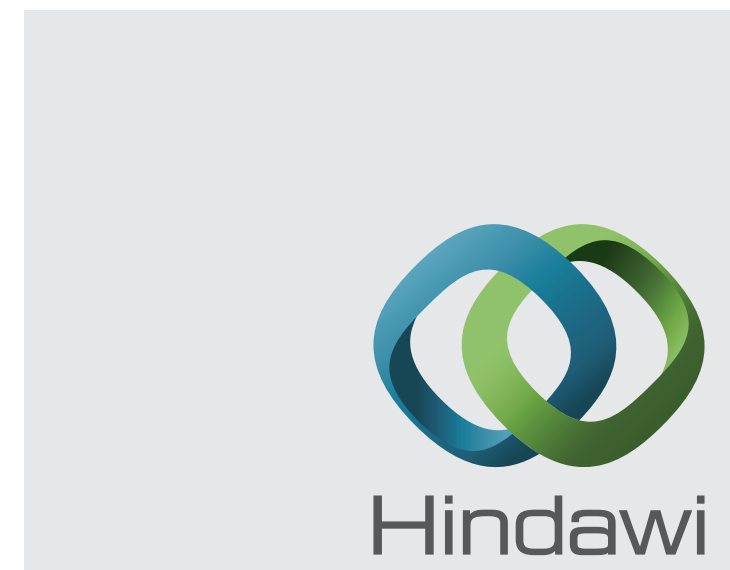

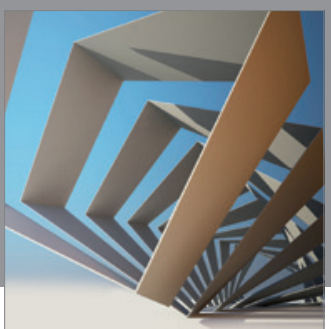

Rotating

Machinery
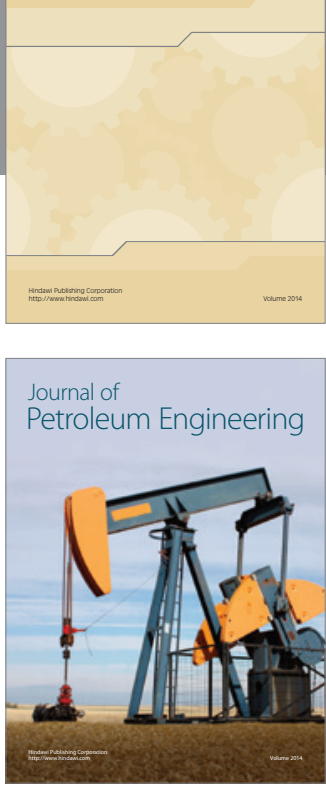

Journal of

Solar Energy
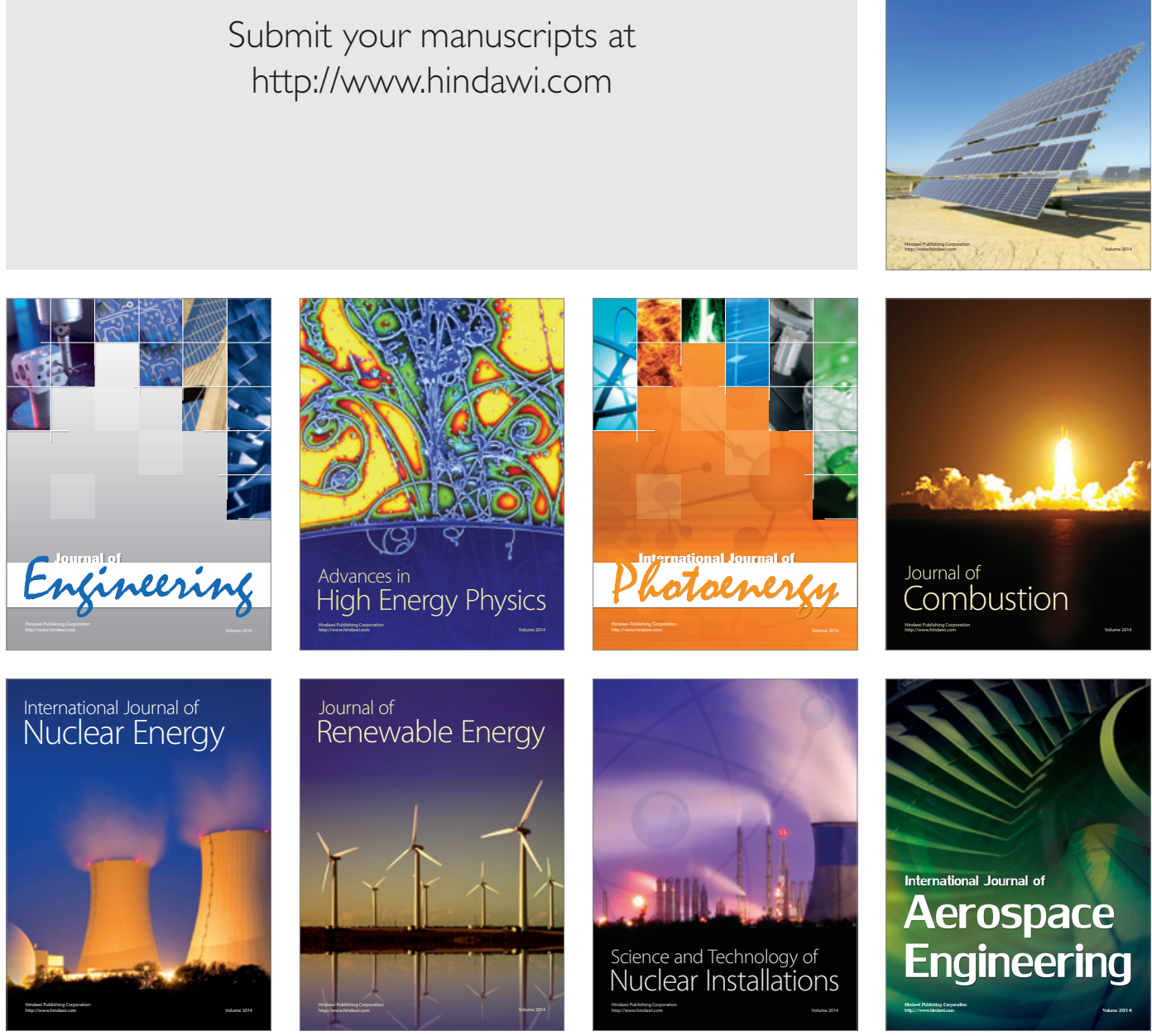